"Um artista da fome" como metáfora de si mesmo e do surgimento de uma nova estética| 133

\title{
"UM ARTISTA DA FOME" COMO METAFORA DE SI MESMO E DO SURGIMENTO DE UMA NOVA ESTÉTICA
}

\author{
Milena Hoffmann Kunrath ${ }^{1}$
}

Resumo: $\mathrm{O}$ artigo analisa o conto "O artista da fome", de Franz Kafka, como uma metáfora do próprio autor, bem como do surgimento de uma nova estética sob o aspecto da dialética do fazer artístico, da relação do criador com seu público e, finalmente, do próprio valor da arte. Embora se concentre numa arte duvidosa, a arte do jejum, as considerações de Kafka são, desta perspectiva, válidas para qualquer tipo de obra artística, inclusive literatura, música, dança, etc. São ainda abordados temas como autenticidade, recepção e aura.

Palavras-chave: Kafka; "Um artista da fome"; estética; arte;

Abstract: The article analyzes the short story "A Hunger Artist", by Franz Kafka, as a metaphor for the author himself, as well as for the emergence of a new aesthetics from the perspective of the dialectics of the artistic production, of the relationship of the creator with his audience, and, finally, of the value of art in itself. Although they focus on a dubious art form, the art of fasting, Kafka's considerations are, from this point of view, valid for any kind of art work, including literature, music, dance, etc. Other themes such as authenticity, reception and aura are addressed. Keywords: Kafka; "A Hunger Artist"; aesthetics; art;

\section{Introdução}

O escritor Franz Kakfa nos oferece reflexões filosóficas sobre uma imensa gama de assuntos. Este investigador da forma desvenda a natureza humana e expõe a solidão do mundo moderno, de maneira a nos reconhecermos em seus escritos. Segundo Carpeaux, não há nada de excepcional na essência de suas narrações, no sentido dos sonhos surrealistas, apenas uma profunda incompreensão diante de equívocos que perturbam a natureza do ser: "Seu tema é a irrupção do extraordinário no mundo ordinário" (CARPEAUX, 1994, p. 289).

${ }^{1}$ Profa. Adjunta UFPel - milena.kunrath@gmail.com 


\section{4 | Milena Hoffmann Kunrath}

Carvalhal (1973), em seu ensaio sobre Kafka e a literatura francesa, aponta a presença dessa dialética também na crítica francesa: "Para Camus, é nesta contradição que reside o segredo de Kafka: nos perpétuos balanços entre o natural e o extraordinário, entre o indivíduo e o universal, entre o trágico e o cotidiano, entre o absurdo e o lógico." (CARVALHAL, 1973, p. 23).

Kafka se revela um pessimista cuja visão de mundo não nos deixa alternativa. Ele "Não acredita em utopias, prefere a antiutopia de um mundo abandonado por Deus" (CARPEAUX, 1994, p. 289). Também encontramos em sua obra um traço profundamente irônico, respaldado pela desesperança.

Além disso, podemos acrescentar uma perspectiva filosófica, no sentido de questionar o que seria naturalmente óbvio para a humanidade em geral. Segundo Anders (1993): "O método de Kafka consiste, pois, em suspender através da troca de etiquetas, os preconceitos ligados a etiquetas, possibilitando, com isso, julgamentos não preconcebidos" (ANDERS, 1993, p. 17).

Dessa forma, o escritor nos permite repensar múltiplos temas que à primeira vista nos forneceriam uma resposta óbvia aos seus problemas.

Um desses temas abordados por Kafka é a análise da arte, sua evolução e conceituação. Em "Um artista da fome", o autor revela diversos paradoxos do fazer artístico e nos conduz metaforicamente ao processo das intensas transformações do valor estético através dos tempos. É importante ressaltar aqui que, quando o escritor se refere à arte, ele se reporta às artes circenses, mas também, indiretamente, à literatura, à música e às artes visuais e, de uma forma mais ampla, à própria estética artística.

A primeira frase do conto já nos revela o teor do que virá a seguir: "Nas últimas décadas o interesse pelos artistas da fome diminuiu bastante (...) Os tempos eram outros" (KAFKA, 1991, p. 23); e orienta o leitor para a mudança de paradigma que virá. Ao longo da tradição humana, testemunhamos alterações em todos os níveis: social, científico, moral, estético etc. Porém, na história recente, em poucas épocas aconteceram transformações tão dramáticas como as da passagem do século XIX para o século XX. O texto de Kafka foi publicado em 1922, no período entre guerras, um pouco antes de sua morte. A humanidade saíra de uma guerra, como nunca vista antes, e enfrentava suas consequências: graves tensões políticas e sociais, a contínua transição de um mundo lento e etéreo para a rapidez da máquina, e a crise econômica constante. Falar sobre a fome como arte num período de fome real nos revela a profunda 
"Um artista da fome" como metáfora de si mesmo e do surgimento de uma nova estética| 135

perspicácia de Kafka, como homem de seu tempo. Como se não bastasse o contexto mundial para a escolha do tema, a trajetória pessoal de Kafka revelaria uma terrível ironia: o autor, um pouco depois, literalmente definharia devido a uma tuberculose laríngea, doença que o impossibilitava de comer.

\section{A honra da arte: autenticidade versus enganação}

Apesar de nos remeter, através do título, à crise da fome, o tema principal do conto é a crise nas artes. As revelações do narradorobservador, que conhece a realidade do artista da fome e nos dá pistas precisas do métier do jejuador, não estão inseridos nem em um tempo, nem em um espaço específicos, mas com exatidão nos colocam a par da definição de seu trabalho, suas exigências e motivações. Nesta narração fragmentária, o testemunho descritivo não mostra seu local de origem, ou seja, não sabemos de onde o narrador olha e analisa, porém, nos é clara a posição do artista em relação a seu ofício. Para Anders (1993),

Essa identificação de homem e profissão, que o mundo moderno trouxe consigo, Kafka a torna plenamente visível inventando profissões absurdas, que fazem o absurdo da identidade de homem e profissão ficar mais claro do que aquelas profissões quotidianas, em face das quais nós não nos espantamos mais com a identidade (ANDERS, 1993, p. $51)$.

O artista da fome, então, apesar da decadência de seu ofício, sempre continuará artista da fome, pois esta é a única coisa que o define. Ou seja, o que está em jogo não é a capacidade do artista em aprender algo novo e assim modificar seu estilo de vida, mas a sua incapacidade de mudar o ser que ele era.

Para o jejuador, sua arte possuía uma honra própria, da qual ele não abria mão. Ao jejuar por tanto tempo, numa exposição que exigia credibilidade, era natural que fosse vigiado, mas o jejuador não comeria nem que pudesse, pois "(...) a honra da sua arte o proibia" (KAFKA, 1991, p. 24). A honra é, porém, relativa: o artista que não enganaria o público comendo escondido, o enganaria de fato, por mostrar o jejum como sacrifício, enquanto, para ele, era muito fácil jejuar: "É que só ele sabia só ele e nenhum outro iniciado - como era fácil jejuar. Era a coisa mais 


\section{6 | Milena Hoffmann Kunrath}

fácil do mundo" (KAFKA, 1991, p. 26). A arte, por sua vez, também é feita do jogo e do logro, do que parece mas não é ${ }^{2}$, de enganar os olhos do apreciador e trazê-lo para um outro nível de experiência. A própria palavra em alemão, da derivação de "arte" nos dá pistas; o suposto adjetivo mais natural derivado de Kunst (arte), seria künstlich, mas este significa "artificial, falso, fingido"; o adjetivo para "artístico" é künstlerisch.

Apesar da arte ser vista aqui como enganação, não é pelo motivo que imaginamos, mais óbvio, que seria comer enquanto se jejua, mas sim pela facilidade do jejum. Para esta preocupação do público, de que o artista realmente não ingerisse nenhum alimento, o narrador do conto descreve uma série pormenorizada de estratégias para demonstrar a idoneidade do espetáculo:

Além dos espectadores que se revezavam, havia ali também vigilantes escolhidos pelo público - em geral, curiosamente, açougueiros, sempre três ao mesmo tempo, e que assumiam a tarefe de observar dia e noite o artista da fome para que ele não se alimentasse por algum método oculto (KAFKA, 1991, p. 24).

A questão da vigilância era levada a sério pelo artista que, embora soubesse que jamais trairia sua arte, precisava constantemente provar sua habilidade. Portanto, quando os vigilantes se distraiam, usava de subterfúgios para que a confirmação de seu empenho famélico não fosse prejudicada: "(...) às vezes, superando a fraqueza, ele cantava, enquanto tinha forças, no período de vigia, para mostrar para as pessoas como era injusto suspeitarem dele" (KAFKA, 1991, p. 24).

Todo o esforço do artista nem sempre trazia resultados, mas ele já estava acostumado à desconfiança do público e sabia que, em relação a sua arte, apenas ele poderia ter absoluta certeza de seu sucesso. O narrador nos explica como funcionavam estas preocupações:

Isso no entanto já fazia parte das suspeita inerente à profissão de artista da fome. Ninguém estava em condições de passar todos os dias e noites ininterruptamente a seu

\footnotetext{
${ }^{2}$ Neste tipo de reflexão, Kafka também foi um precursor. A famosa obra de René Magritte (1898-1967), no final dos anos 1920, Isto não é um Cachimbo (Ceci n'est pas une Pipe), brinca com o conceito da representação em contradição com a natureza real do objeto.
} 
"Um artista da fome" como metáfora de si mesmo e do surgimento de uma nova estética| 137 lado como vigilante, portanto ninguém era capaz de saber, por observação pessoal, se o jejum fora realmente mantido sem falha e interrupção; só o artista podia saber isso e ser o espectador totalmente satisfeito do próprio jejum (KAFKA, 1991, p. 25).

O artista é, então, não apenas a fonte de obra, a principal atração, como também seu público, já que ele deve responder a si próprio com a genuinidade do seu ato de jejuar.

\section{Relação do artista com o público}

O impresario ${ }^{3}$ intermediava a relação do artista com o público. $\mathrm{O}$ artista da fome pensava exclusivamente em sua arte e não se interessava pelos detalhes organizacionais do espetáculo. O empresário havia estabelecido um tempo máximo de 40 dias de jejum:

A experiência mostrava que durante quarenta dias era possível espicaçar o interesse de uma cidade através de uma propaganda ativada gradativamente, mas depois disso o público falhava e se podia verificar uma redução substancial da assistência (KAFKA, 1991, p. 26).

Os 40 dias representam também um número mágico, apesar de basear-se, supostamente, nas observações do empresário, e é possível a óbvia associação na Europa predominantemente cristã da época: foi o mesmo número de dias que Jesus jejuou, como consta na Bíblia, mas ao contrário do artista, em nenhum momento foi considerada uma tarefa fácil. Pelo contrário, o jejum bíblico representou um sacrifício, uma tentação. $\mathrm{O}$ que o artista da fome não compreendia, já que ele queria apenas desenvolver sua arte, era: "Por que parar justamente agora, depois de quarenta dias?" (KAFKA, 1991, p. 27), se ele era capaz de muito mais? $\mathrm{O}$ artista desejava o constantemente o reconhecimento da multidão, se não, poderia jejuar sozinho, apenas com a sua própria consciência, mas a

3 Termo italiano, muito utilizado no alemão entre os séculos XIX e XX, empregado no original por Kafka. 


\section{8 | Milena Hoffmann Kunrath}

presença do público conferia a legitimação de sua arte. Seguia então as recomendações do empresário, embora quisesse oferecer ao público o que acreditava ser o maior espetáculo: "Ele poderia agüentar ainda muito tempo, um tempo ilimitado" (KAFKA, 1991, p. 27). A esta altura, nos é trazida pelo autor do conto outra questão pertinente à evolução do processo artístico, que é a própria existência da obra de arte. Aqui podemos nos questionar se a criação de fato existe, caso não haja legitimação. Tal argumento é válido para as mais diversas expressões artísticas: tanto o artista da fome, com seu jejum sem testemunhas; um livro de gaveta, ou seja, sem leitores; a própria música que nunca foi ouvida; e avançando na vanguarda da arte, as expressões efêmeras dos happenings, cujo testemunho é apenas o registro.

Embora "apenas um registro" pareça um legitimação duvidosa, a obra de arte deve sua existência ao público: não existe literatura de gaveta $^{4}$, espetáculo sem espectadores nem música sem ouvintes; e até mesmo a filosofia ocupa-se desta questão - Se uma árvore cair numa floresta e não houver ninguém por perto para ouvir, ela fará barulho?

Apesar de todos os esforços do artista da fome - bem como os do empresário - a sua arte continuava incompreendida. E o problema, que por muito tempo tinha sido o limite de dias para jejuar (e consequente insatisfação do artista), tornou-se a queda do interesse geral por sua arte: "Seja como for o mimado artista da fome se viu um dia abandonado pela multidão ávida de diversão que preferia afluir a outros espetáculos" (KAFKA, 1991, p. 30).

$\mathrm{O}$ artista não poderia viver sem o reconhecimento do público, mesmo que este não o compreendesse ou valorizasse como ele aspirava. Espera-se do artista, nos dias atuais, constante renovação; o público não está mais acostumado a presenciar diversas vezes o mesmo espetáculo e o artista que não percebe a ansiedade daquele para consumir algo novo, é atropelado pelas novidades. Talvez este sentimento ainda não fosse tão intenso na época em que Kafka escreveu o conto (e em muitos aspectos foi um precursor), mas o que, por muito tempo, foi aceito e admirado passou a ser desprezado e atualmente a expressão atração de circo não representa exatamente um elogio.

O artista da fome encontrava-se ainda mais isolado, pois não dividia suas angústias com seus pares. Ele era incompreendido pelo público, pelo empresário e pelos possíveis colegas de arte, quase como se a arte em si lhe bastasse para tudo. O mesmo vale para Kafka: em nome da

\footnotetext{
${ }^{4}$ livros que nunca foram lidos
} 
"Um artista da fome" como metáfora de si mesmo e do surgimento de uma nova estética| 139 literatura, de sua arte, não foi capaz de relacionar-se com o próximo de uma maneira efetiva e adotou para si a solidão ${ }^{5}$. Mesmo com seus cúmplices das letras tinha uma relação distanciada:

(...) le faltan encuentros decisivos con sus grandes compañeros de letras. Ni siquiera trató personalmente a sus contemporáneos austríacos más importantes: Musil, Hofmannsthal, Rilke o Trakl (WAGENBACH, 1970, p. 9).

Essa reclusão do artista permitiu aos dois, criador e criatura, a dedicação integral à criação, mas, ao mesmo tempo os privou da possibilidade de uma vida real e (supostamente) satisfatória.

Pode parecer estranho aos olhos de hoje, mas a arte do jejum de fato existiu e não faz tanto tempo assim. Ela surgiu no ocidente como espetáculo, com supostos propósitos medicinais, no final do século XIX. O médico Henry Tanner propôs-se a jejuar, tomando apenas água, por 40 dias: ele não apenas sobreviveu, como ficou rico. O controverso médico adquiriu grande fama e descobriu que existia público disposto a pagar para admirá-lo e vigiá-lo durante o seu jejum. Logo o entretenimento passou a vigorar na Europa e muitos adotaram o jejum artístico como forma de alcançar fama e fortuna; entre alguns escândalos, quando a boa fé do público foi ludibriada (comida escondida), a atração passou a contar com diversas técnicas para comprovar a sua idoneidade. $\mathrm{O}$ espetáculo foi comum até o início da Primeira Guerra Mundial: a partir desse momento ninguém mais queria pagar para ver o que era a triste realidade para milhões de pessoas.

As exibições do sofrimento alheio desenvolveram um longo caminho através da história, transformando-se conforme a exigência do público. No Circus Maximum na Roma antiga o público deleitava-se com lutas até a morte; num passado ainda próximo, nos séculos XVIII e XIX, pessoas com deficiência, ou condições médicas especiais, eram exibidas como aberrações interessantes - e é onde se encaixa nosso artista da fome.

\footnotetext{
${ }^{5}$ Sobre Kafka: "Se escrever o condena à solidão, faz de sua existência a existência de um celibatário, sem amor e sem vínculos, se, entretanto, escrever parece-lhe ser - pelo menos com freqüencia e durante largo tempo - a única atividade que poderia justificá-lo, é porque, de todos os modos, a solidão ameaça nele e fora dele, é porque a comunidade não passa de um fantasma, e a lei que ainda fala nela nem mesmo é a lei esquecida mas a dissimulação do esquecimento da lei" (BLANCHOT, 1987, p. 56).
} 


\section{0 | Milena Hoffmann Kunrath}

Segue-se nos dias atuais uma mudança total de paradigma, sendo inaceitável para muitos que os próprios animais permaneçam encarcerados em jaulas para deleite dos espectadores. $O$ narrador nos relata que, após os anos dourados da arte da fome, "(...) em toda parte havia se estabelecido uma repulsa contra o espetáculo da fome" (KAFKA, 1991, p. 30). Alguns saudosistas ainda se lembravam das apresentações gloriosas, mas os mais jovens já não tinham mais a referência para compreender a estética de outra época.

E não era um acaso muito freqüente que um pai de família viesse com seus filhos, apontasse o dedo para o jejuador, explicasse em detalhe do que se tratava, contasse coisas de anos passados, quando presenciara apresentações semelhantes, mas incomparavelmente mais grandiosas e as crianças, em vista do seu preparo insuficiente na escola e na vida, continuavam sem entender - o que significava para elas passar fome? (KAFKA, 1991, p. 32)

A constante renovação artística impele os mais jovens a "destruir" o que parece ter ficado para trás, e os mais velhos a lamentar a insensibilidade diante da legitimidade do que foi desde sempre conhecido. Tal fato ajuda a explicar a incapacidade de compreensão entre valores de diferentes gerações.

\section{Arte como profissão: trabalho versus aura}

Como o próprio título da obra já esclarece, Kafka apresenta o artista da fome, como autor de uma arte, uma capacidade especial destinada a poucos e, da mesma forma compreendida por poucos - "Tente explicar a alguém a arte do jejum!" (KAFKA, 1991, p. 33) - Segundo a academia, a arte exige porém que sua criação não vise a algum objetivo e não seja "fabricada" com a intenção de ser consumida. $\mathrm{O}$ artista da fome deseja manter sua arte pura e deixa para o empresário o preenchimento de questões menos inspiradoras. Aqui apresenta-se novamente um paradoxo do fazer artístico e, principalmente, do fazer artístico do artista da fome: sua arte é valorizada pelo público, pois representa algo que nem todos podem fazer, ou seja uma capacidade que aos outros é impossível; porém, ao artista, o jejuar é fácil. Embora ele não o apregoe, é possível que ninguém acreditasse no fato de o jejuador não ter nenhuma dificuldade para jejuar. 
"Um artista da fome" como metáfora de si mesmo e do surgimento de uma nova estética| 141

Além disso, a própria obra exposta também é capaz de exercer um domínio sobre o público, à revelia do artista. Blanchot (1987) afirma:

Todo escritor, todo artista conhece o momento em que é rejeitado e como que excluído pela obra em curso. Ela mantém-no à margem, está fechado o círculo em que ele não tem mais acesso a si mesmo, onde ele, entretanto, está encerrado, porque a obra, inacabada, não o solta. (BLANCHOT, 1987, p. 48).

O artista da fome já não possui o domínio sobre seu trabalho. Aqui agrava-se ainda o fato de que a sua própria atuação é a sua obra. Ele deseja controlar e expandir seu jejum, mas não tem legitimação para fazêlo. Da mesma forma que as obras que, depois de encerradas, não pertencem mais ao autor, o artista da fome é privado da palavra final sobre seu jejum. Com isso deve enfrentar a insensibilidade de quem não entende de seu ofício, da sua obra e da aura de sua obra:

E quando certa vez, nesse tempo, um ocioso se deteve diante da jaula, escarneceu da velha cifra na tabela e falou de embuste, essa foi, à sua maneira, a mais estúpida mentira que a indiferença e a maldade inata puderam inventar, já que não era o artista da fome quem cometia a fraude - ele trabalhava honestamente - mas sim o mundo que o fraudava nos seus méritos. (KAFKA, 1991, p. 33).

É possível que Kafka não quisesse entregar seus textos à insensibilidade pública. Mas o artista da fome, apesar da crueldade dos espectadores, não deixou de apresentar-se.

Desde o romantismo cultivou-se o mito de que o talento do artista seria algo como um presente de Deus; uma habilidade inata e única que não exigiria nenhum tipo de trabalho ou esforço. Este conceito corresponde à ideia que Benjamin (1994) faz da aura, que seria:

(...) uma figura singular, composta de elementos espaciais e temporais: a aparição única de uma coisa distante, por mais perto que ela esteja. Observar, em repouso, numa tarde de verão, uma cadeia de montanhas no horizonte, ou um galho, que projeta sua sombra entre nós, significa respirar a 


\section{2 | Milena Hoffmann Kunrath}

aura dessas montanhas, desse galho (BENJAMIN, 1994, p. 170).

Próximo à época de Kafka, Benjamin (1994) já dizia, em seu texto escrito em 1936, que a obra de arte estava em declínio devido a capacidade técnica de reproduzir os mesmo efeitos elaborados anteriormente somente pelos artistas. Segundo Kunrath,

A aura seria o objeto de culto ou magia proveniente da tradição de um povo ${ }^{6}$, e a reprodutibilidade do objeto a afastaria de seu valor ritual: desaparece a questão social e cultural e a arte passa a fazer parte de um valor político (KUNRATH, 2009, p. 36).

Ou seja, o resultado passa a perder importância como obra de arte e apenas o seu processo pode conferir à obra seu valor artístico. Para desventura do artista da fome, seu processo perdeu seu valor artístico, e ele não compreendia de que forma - "Era impossível lutar contra essa incompreensão, contra esse mundo de insensatez." (Kafka 1991:29) -, mas não pela facilidade de reprodução, e sim pela mudança de apreciação estética.

Kafka também é um artista em descompasso com seu tempo, mas ao contrário do artista da fome, que já se encontrava ultrapassado, o escritor foi um precursor pouco compreendido em seu tempo. Segundo Carvalhal (1973):

E se tradicionalmente cabe sempre ao verdadeiro artista intuir e conscientizar antes dos outros a problemática de sua época, Kafka parecia, em 1939, ter ultrapassado essa atitude: ao intuir os problemas em germe no seu tempo e em sua condição, teria previsto os fatos terríveis que atormentariam o homem de décadas posteriores (CARVALHAL, 1973, p. 17).

6 "[...] o valor único da obra de arte "autêntica" tem sempre um fundamento teológico, por mais remoto que seja: ele pode ser reconhecido, como ritual secularizado, mesmo nas formas mais profanas do culto do Belo.” (Benjamin 1994:171) 
"Um artista da fome" como metáfora de si mesmo e do surgimento de uma nova estética| 143

Podemos certamente afirmar que Kafka não previu os desdobramentos que ocasionariam a Segunda Guerra Mundial, mas como artista foi capaz de antecipar o desequilíbrio europeu e também, na esfera pessoal, o sentimento de inadequação do homem moderno.

\section{A arte como eterna insatisfação}

Para falarmos de arte, como conceito atual, é necessário voltarmos no tempo. Tanto a Literatura, quanto a Arte (e a Música) desenvolvem-se ${ }^{7}$ através de rupturas. Quando o máximo de uma tendência é alcançado, mesmo que nem todos, ou a grande maioria, não se dê conta, o movimento (literário, artístico, musical) acha formas de "desengessar" a teoria criada em cima da "última moda". Para isso, os conceitos ditos modernos (ou, para cada época, atuais) encontram meios de combater a crença anterior. Os chamados períodos literários alternam-se entre apolíneos e dionisíacos: quanto mais diferente do movimento anterior, melhor. Enquanto na Literatura a grande ruptura surgiu com o Romantismo, na Arte, as escolas artísticas ${ }^{8}$ do final do século XIX, assumiram o papel de questionadoras, mudando completamente o conceito de Arte (KUNRATH, 2009, p. 37).

A eterna busca pela obra de arte completa é uma falácia, pois o que move o artista é a infinitude de sua satisfação. Depois de supostamente satisfazer sua indagação e estabelecer novos paradigmas, aquilo não será mais suficiente para o artista que genuinamente almeja

\footnotetext{
${ }^{7}$ Não me refiro a um desenvolvimento como melhoria ou evolução, mas, sim, como mudança.

8 Tais escolas preocupavam-se mais com os pensamentos e reflexões que suas manifestações pudessem suscitar, do que com o valor artístico, comercial e temporal de cada obra de arte criada. Por isso o valor das obras do período referese a sua aparição e não ao objeto em si. Genette, no livro "A Obra de Arte", explica um pouco esta relação, a respeito de um ready-made: "[...]o fato de um porta-garrafa ter cinqüenta ou sessenta hastes, ou o tom exato de seu metal, não importa, sem dúvida, para sua significação artística...”, “[...] o que conta neste gênero de obras não é nem o objeto proposto em si mesmo, nem o ato da proposição em si mesmo, mas a idéia desse ato.” (p. 136)
} 


\section{4 | Milena Hoffmann Kunrath}

que sua obra não tenha fim. Blanchot refere-se, nesse sentido, à arte da escrita:

O escritor nunca sabe que a obra está realizada. O que ele terminou num livro, recomeçá-lo-á ou destruí-lo-á num outro. Valéry, celebrando na obra esse privilégio do infinito, ainda vê nela o lado mais fácil: que a obra seja infinita, isso significa (para ele) que o artista, não sendo capaz de lhe pôr fim, é capaz, no entanto, de fazer dela o lugar fechado de um trabalho sem fim, cujo inacabamento desenvolve o domínio do espírito, exprime esse domínio, exprime-o desenvolvendo-o sob a forma de poder (BLANCHOT, 1987, p. 11).

E continua, em seguida, elucidando o estímulo primeiro da obra: "Entretanto, a obra - a obra de arte, a obra literária - não é acabada nem inacabada: ela é. O que ela nos diz é exclusivamente isso: que é - e nada mais" (BLANCHOT, 1987, p. 12).

O artista da fome vê seu declínio como oportunidade e deseja mostrar a todos como pode se superar. Ele tem um plano para impressionar a todos e reconquistar sua antiga fama - " (...) afirmava até que, se o deixassem fazer sua vontade (...) desta vez ia encher o mundo de justificado espanto (...)" (KAFKA, 1991, p. 31) - mas não percebe que todo esforço é em vão.

Em sua ânsia para se superar, o artista, agora trabalhando em um circo com um contrato que o liberava do regime de quarenta dias, podia jejuar sem fim. Acreditando que a nova modalidade de jejum pudesse atrair novamente o interesse do público, mas, ao mesmo tempo, sentindose livre das regras impostas pelo empresário - e consequentemente, do próprio público -, o artista desligou-se da realidade que o cercava, do delicado equilíbrio entre as intenções e o resultado do artista, e de sua recepção. O pobre artista não percebeu que, sendo ignorado, a sua arte deixaria de existir. Blanchot comenta sobre a obra sem público:

O escritor escreve um livro mas o livro ainda não é a obra, a obra só é obra quando através dela se pronuncia, na violência de um começo que lhe é próprio, a palavra ser, evento que se concretiza quando a obra é a intimidade de alguém que a escreve e de alguém que a lê (BLANCHOT, 1987, p. 13). 
O escritor de "O Artista da fome" praticamente só concretizou sua obra postumamente. Embora tivesse algumas obras publicadas em vida, seus principais romances, e a importância devida, só aparecem anos depois da morte do autor. Além disso, também era o desejo de Kafka que suas obras não fossem publicadas. Por algum motivo, o artista queria privar seu público e crítica de sua produção.

No meio de inúmeras outras atrações, o artista da fome foi sendo esquecido, pelo público e pelo seu empregador, conforme a triste descrição:

Os belos cartazes ficaram sujos e ilegíveis, foram arrancados, não ocorreu a ninguém substituí-los; a pequena tabela com o número dos dias de jejum, que nos primeiros tempos era cuidadosamente renovada, continuava a mesma há muito tempo, pois após as primeiras semanas os próprios funcionários não quiseram mais se dar nem a este pequeno trabalho (KAFKA, 1991, p. 33).

Quando é descoberto em sua jaula, em meio à palha, quase morto, o artista faz aos funcionários uma última confissão - "Eu sempre quis que vocês admirassem meu jejum (...)" (KAFKA, 1991, p. 34) - , e é incrivelmente irônico que esta confissão chegue a pessoas que não conhecem sua arte, não são capazes de compreender do que o artista está falando, não se importam com o assunto e nem mesmo acreditam na sanidade dele. Mas através destas últimas palavras, o leitor é alertado da motivação do artista e o segredo de seu talento: "Porque eu não pude encontrar o alimento que me agrada. Se eu o tivesse encontrado, pode acreditar, não teria feito nenhum alarde e me empanturrado como você e todo o mundo" (KAFKA, 1991, p. 34). O artista não se valia do seu trabalho, nem mesmo de sua vocação para desenvolver sua arte, mas simplesmente um acaso infeliz (a inapetência por todo tipo de comida) gerou seu admirado talento. Como uma punição, a habilidade (ou maldição) gratuita não foi mais, depois de algum tempo, suficiente.

\section{Nova atração}

A jaula do artista logo foi destinada a uma nova atração que, apesar de ser de alguma forma incômoda, não deixava de atrair um 


\title{
146 | Milena Hoffmann Kunrath
}

grande público. "E a alegria de viver brotava da sua garganta com tamanha intensidade que para os espectadores não era fácil suportá-la. Mas eles se dominavam, apinhavam-se em torno da jaula e não queriam de modo algum sair dali" (KAFKA, 1991, p. 35).

Uma jovem pantera, com fome de vida, substitui o artista que desvaneceu-se lentamente, já sem fôlego para lutar por sua posição.

Seguindo esta premissa, podemos imaginar que a pantera será, algum dia, substituída. Existem, porém, artistas que não deixam de comunicar (através de sua obra), mesmo que sua suposta "época" tenha passado. Kafka foi um pioneiro em muitos dos incômodos temas que tocam a alma humana em nossos dias e permanece atual a cada leitura. Segundo Carvalhal,

\begin{abstract}
(...) de uma problemática essencialmente pessoal, a obra de Kafka, pela sua arte, foge aos limites que normalmente a restringiriam e garante ainda hoje sua atualidade. Porque, mesmo sem ser intencional, a crise de Franz Kafka configurar-se-ia como à do homem moderno, a sua solidão aparentar-se-ia unido homem consciente e a sua angústia pessoal seria o drama universal da condição humana (CARVALHAL, 1973, p. 19).
\end{abstract}

Entendemos então que, pela sua qualidade, uma obra pode continuar significando, embora sua fórmula já não possa mais ser repetida. Da mesma forma que os artista figurativos, com suas imagens que imitavam a vida, não perderam o valor, qualquer um que pinte como eles (ou até mesmo a fotografia, que gera o mesmo resultado), nos dias de hoje, não terá a mesma relevância.

Nos escritos de Kafka encontram-se muitas referências a animais, desde o monstruoso inseto de "A metamorfose", até a rata de um dos seus últimos contos, "Josefina, a cantora, ou $\mathrm{O}$ povo dos camundongos". $\mathrm{Na}$ verdade, em sua grande parte, o leitor nem mesmo sabe a que animal o escritor se refere: ao contrário do mito já estabelecido na cultura contemporânea, Kafka nunca mencionou uma barata em sua "A metamorfose", e o ser do conto "A toca" (que muitas vezes é tratado como um texugo, mas, da mesma maneira que em "A metamorfose" nunca é nominalmente citado), pensa como um ser humano mas possui predominantes características animais. A preferência do escritor por personagens que representam animais, mas agem como humanos, nos apresenta um mundo particular onde as fronteiras não são tão bem 
"Um artista da fome" como metáfora de si mesmo e do surgimento de uma nova estética| 147 definidas quanto acreditamos. Esta hibridez tenciona expor-nos ao fato de que homens e animais não são tão diferentes assim e podem ser confundidos: a pantera e o artista da fome são atrações expostas para os mesmos fins, pondo em questão, assim, nossos instintos mais profundos.

\section{Conclusão}

Kafka é, sem dúvida, um pessimista em relação ao mundo e aos desdobramentos da vida. Ele não acredita em redenção, mas sabemos que a arte em sua vida era uma necessidade. Blanchot (1987), em relação a Kafka, afirma que "(...) a literatura anuncia-se como o poder que emancipa, a força que afasta a opressão do mundo, (...)" (BLANCHOT, 1987, p. 68), e continua: "Escrever é conjurar os espíritos, é talvez libertálos contra nós, mas esse perigo pertence à própria essência do poder que liberta" (BLANCHOT, 1987, p. 68). O ensaísta concebe ainda a existência e realização de Kafka apenas como literária.

O escritor é capaz de nos fazer questionar toda sorte de afirmações categóricas, graças à sua inclinação pelo absurdo verossimilhante. Os estereótipos e os critérios massificados para qualquer crença são questionados.

$\mathrm{Na}$ leitura do conto, a construção de Kafka permite que nos aproximemos de diversas questões relevantes no estudo da grande variedade de manifestações artísticas, inclusive a escritura do próprio autor. Se partirmos do princípio de que estas possuem parâmetros aproximadamente comuns, no que concerne à sua evolução, percebemos a genialidade do escritor, ao falar de seus próprios questionamentos.

Tematizando a recorrente e necessária crise no mundo das artes através de um conto aparentemente singelo, Kafka indaga a respeito dos padrões estéticos de sua época e ainda de seu próprio fazer artístico.

O autor foi, em diversas frentes, um precursor, ao perceber, mesmo que de forma involuntária, e explorar em sua obra a essência do que ainda estava por acontecer. Em sua descoberta como autor, apenas após sua morte (em alguns lugares, muito depois ${ }^{9}$ ), a sua obra tornou-se

\footnotetext{
${ }^{9}$ A obra de Kafka, nos anos 1920, era de conhecimento restrito, apenas por um pequeno círculo de iniciados, falantes de língua alemã. Foi introduzida na França por Breton e posteriormente, Camus e Sartre até chegar à Inglaterra e América do Norte. Apenas nos anos 1950 a obra chegou à Alemanha e até 1957 não havia versões publicadas, da maioria dos livros de Kafka, para o tcheco.
} 


\section{8 | Milena Hoffmann Kunrath}

extremamente relevante, graças, principalmente, à sua atualidade em relação ao mundo moderno. Carvalhal (1973) comenta que,

Este paradoxo pode ser compreendido se considerarmos que cada obra artística tem o seu momento, ou seja, a ocasião em que ecoa com profundidade e ressonância, embora, às vezes, raras, é certo, seja criada com antecedência histórica (CARVALHAL, 1973, p. 15).

A autora foi precisa quando explicita a raridade da perspicácia do escritor em relação ao momento posterior, que ele jamais testemunharia, e completa desta forma: "O que de qualquer maneira surpreende e subjuga é a atualidade penetrante que o escritor de Praga colocara 20 ou 30 anos antes" (CARVALHAL, 1973, p. 21).

Dito isso, é natural que percebamos Kafka como o injustiçado e incompreendido artista da fome, mas nada poderia estar mais equivocado. Da mesma maneira que a farsa do artista da fome não é a que seu público acredita - burlar o jejum -, mas sim a falta de uma comida que lhe apetecesse, Kafka não representa o artista da fome apesar de ter morrido de inanição e sofrer, como artista, de uma constante insatisfação -, mas sim, a pantera: o ser ameaçador que parece estranho a seus pares e os desafia, ainda que timidamente, e estando alheio à sua volta, a enfrentar a nova realidade. Não sendo o dono de uma arte decadente e datada, como o artista da fome, ele instiga seu público, o atrai com a promessa de algo nunca visto antes, desperta o medo, mas não a repulsa. A fome de vida da pantera é, de certa forma, indiferente ao seu público: desde que alimentada, sua existência não depende da aceitação alheia.

Seguindo nesta linha de pensamento, poderíamos pensar que Kafka pudesse, depois do auge de sua fórmula e o estabelecimento de sua estética, ser gradualmente esquecido, como fora anteriormente o artista da fome. Porém, a qualidade de sua obra não o permite. Sua forma de ver o mundo pertence ao cânone por sua infinitude: ela não parece esgotar-se e já se desprendeu há muito do autor; ela é capaz de gerar, infinitamente, inúmeros sentidos. 
"Um artista da fome" como metáfora de si mesmo e do surgimento de uma nova estética| 149

\section{REFERÊNCIAS BIBLIOGRÁFICAS}

ANDERS, Günter. Kafka: pró e contra. Tradução de Modesto Carone. São Paulo: Perspectiva, 1993.

BENJAMIN, Walter. Magia e técnica, arte e política: ensaios sobre literatura e história da cultura. Tradução de Sérgio Paulo Rouanet. 7.ed. São Paulo: Brasiliense, 1994.

BLANCHOT, Maurice. O espaço literário. Tradução de Álvaro Cabral. Rio de Janeiro: Rocco, 1987.

CARPEAUX, Otto Maria. Literatura alemã. São Paulo: Nova Alexandria, 1994.

CARVALHAL, Tania Franco. Franz Kakfa e a literatura francesa. In: A realidade em Kafka. Porto Alegre: Movimento, 1973. p.13-41.

GENETTE, Gérard. A obra de arte: imanência e transcendência. São Paulo: Littera Mundi, 2001.

KAFKA, Franz. Um artista da fome e A construção. Tradução de Modesto Carone. São Paulo: Brasiliense, 1991.

KUNRATH, Milena Hoffmann. Günter Grass, Oskar e seus tambores:a tradução de uma prática interdisciplinar. Dissertação (Mestrado). Universidade Federal do Rio Grande do Sul, Instituto de Letras, Programa de Pós-Graduação em Letras, Porto Alegre, 2009.

WAGENBACH, Klaus. Kafka en testimonios personales y documentos gráficos. Madrid: Alianza Editorial, 1970.

Recebido em 04 de julho de 2016.

Aceito em : 10 de dezembro de 2016. 